\title{
SIMULTANEOUS DETERMINATION OF PROPRANOLOL HYDROCHLORIDE AND FLUNARIZINE DIHYDROCHLORIDE IN BULK AND CAPSULE USING REVERSED - PHASE HIGH -PERFORMANCE THIN LAYER CHROMATOGRAPHY / DENSITOMETRY
}

\author{
AMOD S. PATIL, ATUL A. SHIRKHEDKAR*, SANJAY J. SURANA, PRAJAKTA S. NAWALE \\ R.C. Patel Institute Pharmaceutical Education and Research, Shirpur Dist: Dhule (MS) 425405 \\ (Received: July 14, 2011 - Accepted: September 8, 2011)
}

\begin{abstract}
A simple, rapid and sensitive RP- HPTLC method has been established for the determination of Propranolol hydrochloride (PRH) and Flunarizine Dihydrochloride (FNZ) in bulk and capsule formulation. Separation of both these drugs were achieved on aluminum backed silica gel 60 RP-18 $\mathrm{F}_{254} \mathrm{~S}$ HPTLC plates, prewashed with methanol using methanol: toluene: ammonia (7:3:0.5 v/v) as mobile phase. Densitometric scanning was performed at $267 \mathrm{~nm}$. The $\mathrm{R}_{\mathrm{f}}$ values for PRH and FNZ were found to be 0.63 and 0.48 , respectively. The amount of PRH and FNZ estimated in capsule formulation were found to be $99.20 \pm$ 1.04 and $98.89 \pm 1.23$, respectively. The accuracy of the method was found to be in the range of $99.30-100.41 \%$ for PRH and $99.56-100.87$ for FNZ. The method was validated as per ICH guidelines and can regularly used for analysis of PRH and FNZ in capsule dosage form.
\end{abstract}

Keywords: Propranolol hydrochloride, Flunarizine dihydrochloride, RP- HPTLC

\section{INTRODUCTION}

The combination of Propranolol hydrochloride( PRH) and Flunarizine Dihydrochloride(FNZ) is used in treatment of migraine ${ }^{1}$.

PRH , 1-(isopropylamino)-3-(1-naphthyloxy)-2-propanol, is a non selective $\beta$ blocker $^{2}$. It is used in management of hypertension, angina pectoris, and cardiac arrhythmias ${ }^{3}$.

Many analytical methods for determination of propranolol have been described such as HPLC ${ }^{4}$, UV - spectrophotometric ${ }^{5}$ and HPTLC ${ }^{6}$ methods.

Flunarizine (FNZ), (E)-1-[Bis(4-fluorophenyl) methyl]-4-(3-phenyl2-propenyl) piperazine ${ }^{7}$, is difluorinated derivative of cinnarizine. It has antihistamine, sedative and calcium channel blocking activity ${ }^{3}$. Several analytical methods such as GC ${ }^{8}$, HPLC ${ }^{9}$, and UV - spectrophotometric ${ }^{10}$ methods have been reported in bulk, pharmaceutical dosage form and in biological fluids for determination of FNZ.

For analysis of both these drugs in their capsule dosage form UVspectrphotometric method has been reported ${ }^{11}$.

To our notice, so far no HPTLC method has been reported for the simultaneous determination of PRH and FNZ in their combined dosage form.

Therefore, in the present communication an attempt has been made to develop a simple, rapid and precise RP - HPTLC method for simultaneous determination of PRH and FNZ in combined capsule dosage form and validation of developed RP-HPTLC method.

\section{EXPERIMENTAL}

\section{Chemicals and Reagents}

Pharmaceutical grade Propranolol Hydrochloride (purity, 99.80\%) and Flunarizine Dihydrochloride (purity, $99.85 \%$ ) working standards were obtained as generous gifts from Alkem Pharm., Mumbai, India. Methanol (A.R. Grade) was purchased from Merck Ltd., Worli, Mumbai, India. Capsule (BETACAP PLUS 10) was purchased from local market, containing PRH $40 \mathrm{mg}$ and FNZ $10 \mathrm{mg}$ per capsule.

\section{Instrumentation}

The plates were prewashed with methanol and activated at $110^{\circ} \mathrm{C}$ for $5 \mathrm{~min}$, prior to chromatography. The linear ascending development was carried out in $20 \times 10 \mathrm{~cm}$ twin trough glass chamber (Camag, Muttenz, Switzerland) using methanol: toluene: ammonia $(7: 3: 0.5 \mathrm{v} / \mathrm{v})$ as mobile phase, after saturation of the chamber with mobile phase vapor for $25 \mathrm{~min}$. The development distance was $8 \mathrm{~cm}$. After, chromatography plates were dried in a current of air with the help of air dryer. A Camag HPTLC system containing Camag Linomat 5 sample applicator, Hamilton syringe $(100 \mu \mathrm{L})$, Camag TLC Scanner-3 with winCATS software version 1.3.0 and Camag twin- trough chamber $(20 \times$ $10 \mathrm{~cm}$ ) were used for the present study. The source of radiation utilized was deuterium lamp emitting a continuous UV spectrum between 200 to $400 \mathrm{~nm}$.

\section{Preparation of standard solution}

Mixed stock standard solution was prepared by dissolving $40 \mathrm{mg}$ of PRH and $10 \mathrm{mg}$ of FNZ in $50 \mathrm{~mL}$ of methanol to get concentration of $0.8 \mathrm{mg} / \mathrm{mL}$ and $0.2 \mathrm{mg} / \mathrm{mL}$, respectively.
Selection of analytical wavelength

After chromatographic development bands were scanned over the range of $200-400 \mathrm{~nm}$ and the spectra were overlain; as good resolution and reproducible results were obtained when the both these drugs were estimated at $267 \mathrm{~nm}$.

Preparation of calibration curves

From the mixed stock standard stock solution, 1- $6 \mathrm{~mL}$ was transferred into series of six volumetric flasks and volume was made up to the mark with methanol. From each volumetric flask a volume of $10 \mu \mathrm{L}$ was applied on RPHPTLC plate to obtain series of concentration $800-4800 \mathrm{ng}$ per band of PRH and $200-1200 \mathrm{ng}$ per band of FNZ. The plates were developed and scanned as described under above established chromatographic conditions. Each standard in six replicates was analyzed and peak areas were recorded. Calibration curves of PRH and FNZ were plotted separately of peak area vs. respective concentration of PRH and FNZ.

\section{Analysis of capsule formulation}

The content of twenty capsules were accurately weighed and crushed into fine powder. A quantity of powder equivalent to $40 \mathrm{mg}$ of PRH and $10 \mathrm{mg}$ of FNZ was weighed and transferred to a $50 \mathrm{~mL}$ volumetric flask containing approximately $25 \mathrm{~mL}$ of methanol, ultrasonicated for $5 \mathrm{~min}$, and volume was made up to the mark with the methanol. The solution was filtered through Whatman 41 filter paper, and $3 \mathrm{~mL}$ of filtrate was further diluted to $10 \mathrm{~mL}$ with methanol. Then, volume of $10 \mu \mathrm{L}$ was applied to a TLC plate. After chromatographic development the peak areas of the bands were measured at $267 \mathrm{~nm}$ and the amount of each drug present in sample was estimated from the respective calibration curves. Procedure was repeated six times for the analysis of homogenous sample.

\section{RESULTS AND DISCUSSION}

\section{Mobile phase optimization}

Mobile phases containing various ratios of methanol, toluene i.e. 8:2 v/v and 7:3 $v / v$ were tried to give compact spot for FNZ and for PRH tailing of spot was observed. To rule out the problem, small proportion of ammonia was added. Finally, the mobile phase containing methanol: toluene: ammonia (7:3:0.5, v/v) was selected as optimal for obtaining well defined and resolved peaks. The optimum wavelength for detection and quantitation used was 267 $\mathrm{nm}$ (figure 1). The retention factors for PRH and FNZ were found to be $0.63 \pm$ 0.03 and $0.48 \pm 0.03$, respectively. Representative densitogram obtained from a mixed standard solution of PRH and FNZ is shown in (Figure 2).

\section{Validation}

The method was validated by establishing linearity, robustness, ruggedness, specificity, accuracy, inter day and intra- day precision of measurement of sample application. The limit of detection and limit of quantification were also determined.

\section{Calibration curve}

Linearity was studied in the concentration range from 800 to $4800 \mathrm{ng}$ per band for PRH and 200 to 1200 ng per band for FNZ. Both the drugs showed good linearity in the tested range. The regression equations for PRH and FNZ were found to be $\mathrm{y}=2.052 \mathrm{x}+1397$ and $\mathrm{y}=5.253 \mathrm{x}+868.4$. The regression 
co-efficient $\left(\mathrm{r}^{2}\right)$ value for PRH and FNZ was found to be $>0.997$

Robustness and Ruggedness

Robustness of the method was determined by small considerable changes in mobile phase volume, mobile phase composition, development distance and chamber saturation period. Robustness of the method was performed at a concentration level of 2400 and $600 \mathrm{ng}$ per band for PRH and FNZ. When very small changes were made to the method conditions there were no marked changes in chromatographic behavior and content of the drug, as evident from the low value of percentage RSD indicating the method is robust. (Table 1)

Ruggedness test was determined between two different analysts. The value of percentage RSD was below $2.0 \%$, showed ruggedness of developed analytical method.

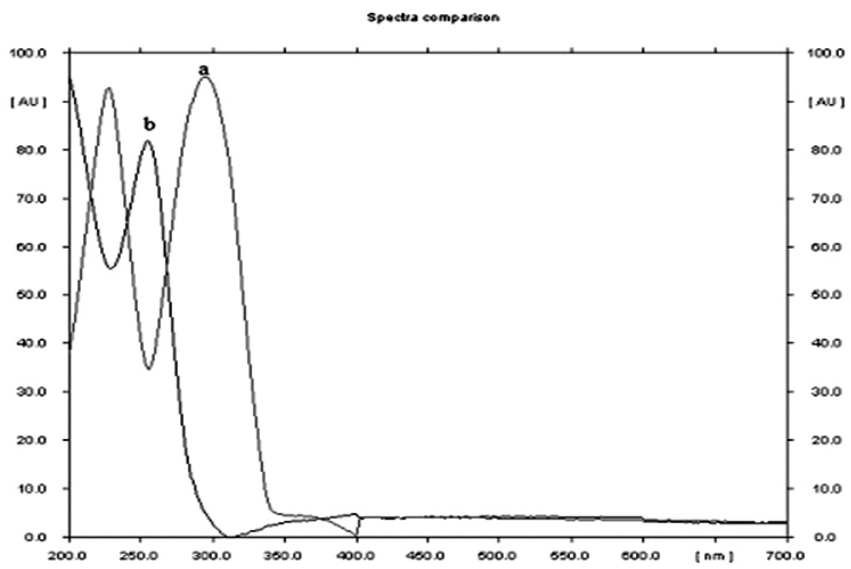

Figure 1: Typical overhin spectra of PRH (a) and FNZ (b) stand ard solutions.

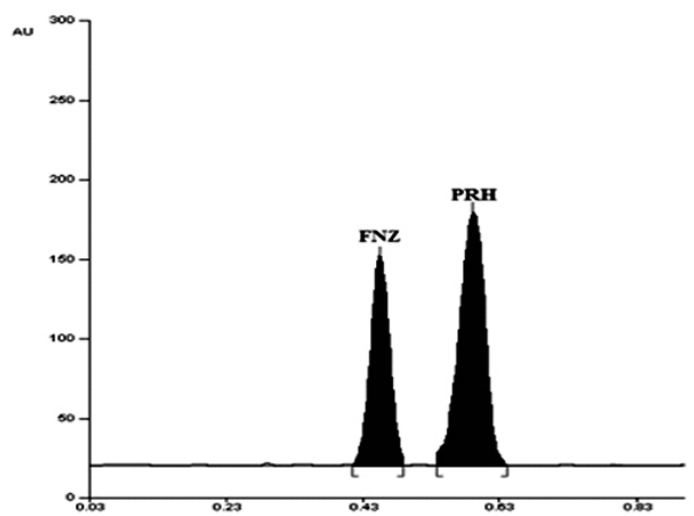

Figure 2. Densitogram of FNZ (400 ng per band, Rf $0.48 \pm 0.03$ ) and PRH (1600ng per band, Rf $0.63 \pm 0.03)$ in methanol: toluene: ammonia $(7: 3: 0.5 \mathrm{v} / \mathrm{v})$

Table 1: Robustness studies.

\begin{tabular}{|c|c|c|}
\hline \multirow{2}{*}{ Parameters } & PRH & FNZ \\
\cline { 2 - 3 } & \% RSD $(\mathrm{n}=6)$ & \%RSD \\
\hline Mobile phase volume & 1.20 & 1.35 \\
\hline Mobile phase composition & 0.77 & 1.49 \\
\hline Development distance & 0.84 & 1.42 \\
\hline Duration of saturation & 0.91 & 1.34 \\
\hline
\end{tabular}

Specificity

There was no interference from sample placebo in peak purity of PRH and FNZ. It showed that developed method was specific for the analysis of PRH and FNZ in capsule dosage form.

Limit of Detection (LOD) and Limit of Quantification (LOQ)

The LOD and LOQ were calculated using equations; $\mathrm{LOD}=3.3 \times \mathrm{N} / \mathrm{B}$ and
$\mathrm{LOQ}=10 \times \mathrm{N} / \mathrm{B}$, where, $\mathrm{N}$ is standard deviation of the peak areas of the drugs $(\mathrm{n}=3)$, taken as a measure of noise, and ' $\mathrm{B}$ ' is the slope of the corresponding calibration curve. The LOD and LOQ for PRH were found to be $24.84 \mathrm{ng}$ and $75.30 \mathrm{ng}$, respectively. For FNZ, LOD and LOQ were found to be $15.91 \mathrm{ng}$ and $48.23 \mathrm{ng}$, respectively

Precision and Accuracy

Precision of the method was studied as repeatability and intra-day and inter-day variations. The repeatability of sample application and measurement of peak area was determined by performing six replicate measurements of 2400 $\mathrm{ng} / \mathrm{band}$ for PRH and $600 \mathrm{ng} / \mathrm{b}$ and for FNZ; the effects on the results were studied in terms of \%RSD and found to be less than 2 .

Intra-day variation was determined by analyzing three different concentrations for three times within a day and Inter-day precision was assessed by three different concentrations for three different days, over a period of week.

The intra-day and inter-day variation were measured at three different concentrations 1600, 2400, $3200 \mathrm{ng} / \mathrm{band}(\mathrm{PRH})$ and 400, 600, $800 \mathrm{ng} / \mathrm{band}$ (FNZ). The effects on results of intra-day and inter-day variations were assessed in terms of \%RSD; found to be less than 2 .

The accuracy of the experiment was established by spiking pre-analyzed sample with known

amounts of the corresponding drugs at three different concentration levels i.e. 80,100 and $120 \%$

of the drug in the capsule. The spiked samples were then analyzed for six times. The mean recovery is within acceptable limits, indicating the method is accurate. (Table 3).

The low values of $\% \mathrm{RSD}$ indicative of the method is precise and accurate.

Table 3: Recovery Studies.

\begin{tabular}{|c|c|c|c|c|c|}
\hline $\begin{array}{c}\text { Compo- } \\
\text { nents }\end{array}$ & $\begin{array}{c}\text { Initial } \\
\text { Amount } \\
\text { (ng per } \text { band })\end{array}$ & $\begin{array}{c}\text { Sample } \\
\text { level } \\
\text { Added } \\
(\%)\end{array}$ & $\begin{array}{c}\text { Amount recovered } \\
\pm \text { S.D. [ng per } \\
\text { band] n=3 }\end{array}$ & $\begin{array}{c}\% \\
\text { Recov- } \\
\text { ered }\end{array}$ & $\begin{array}{c}\% \\
\text { RSD }\end{array}$ \\
\hline \multirow{4}{*}{ PRH } & 1600 & 80 & $1273 \pm 13.49$ & 99.52 & 1.05 \\
\cline { 2 - 6 } & 1600 & 100 & $1606 \pm 20.61$ & 100.41 & 1.28 \\
\cline { 2 - 6 } & 1600 & 120 & $1906 \pm 14.45$ & 99.30 & 0.75 \\
\hline \multirow{4}{*}{ FNZ } & 400 & 80 & $322.81 \pm 4.48$ & 100.87 & 1.38 \\
\cline { 2 - 6 } & 400 & 100 & $399.34 \pm 5.80$ & 99.83 & 1.45 \\
\cline { 2 - 6 } & 400 & 120 & $477.89 \pm 3.06$ & 99.56 & 0.64 \\
\hline
\end{tabular}

n- number of determinations

Different validation parameters for RP- HPTLC method are summarized in (Table 4).

Table 4: Summary of validation parameters.

\begin{tabular}{|c|c|c|}
\hline \multirow{2}{*}{ Parameter } & \multirow{2}{*}{ PRH } & \multirow[b]{2}{*}{ FNZ } \\
\hline & & \\
\hline Linearity Range [ ng per band] & $800-4800 \mathrm{ng}$ & $200-1200 \mathrm{ng}$ \\
\hline Correlation coefficient & 0.997 & 0.997 \\
\hline Limit of detection [ng] & 24.84 & 15.91 \\
\hline Limit of quantification [ng] & 75.30 & 48.23 \\
\hline \multicolumn{3}{|l|}{ Precision (\%RSD) } \\
\hline Intra-day $[\mathrm{n}=6]$ & $0.37-1.11$ & $0.65-1.48$ \\
\hline Inter-day $[\mathrm{n}=6]$ & $0.57-1.31$ & $0.79-1.95$ \\
\hline Repeatability $[\mathrm{n}=6]$ & 1.68 & 1.88 \\
\hline \multicolumn{3}{|l|}{ Ruggedness [\%RSD] } \\
\hline Analyst $1[n=6]$ & 1.50 & 1.73 \\
\hline Analyst $2[\mathrm{n}=6]$ & 0.90 & 1.40 \\
\hline
\end{tabular}

\section{Analysis of capsule formulation:}

Using the proposed chromatographic method, assay of PRH and FNZ in their capsules (BETACAP PLUS 10, label claim: $40 \mathrm{mg}$ PRH and $10 \mathrm{mg}$ FNZ per capsule) was carried out. The peaks at $R_{\mathrm{f}} 0.63$ for PRH and $R \mathrm{f} 0.48$ for FNZ were observed in the densitogram of the drug samples extracted from capsules. There was no interference from the excipients commonly present in the capsules. The drug content was found to be $99.20 \%$ and $98.89 \%$ for PRH and FNZ, respectively. 


\section{CONCLUSION}

The proposed method is simple, accurate, cost effective, less time consuming. Statistical analysis proved that the method is reproducible and efficient for the simultaneous estimation of PRH and FNZ as bulk drugs and in combined pharmaceutical dosage forms without any interference from the excipients.

\section{ACKNOWLEDGEMENT}

The authors are thankful to R.C. Patel Institute of Pharmaceutical Education and Research, Shirpur Dist: Dhule (MS) 425405

\section{REFERENCES}

1. C. A. Bordini, M. A. Arruda, M. C. Ciciarelli, J. G. Speciali, Arq. Neuropsiquiatr. 55 (3-B), 536, (1997)

2. Indian Pharmacopeia, Ministry of Health and Family Welfare, Government of India, The Indian Pharmacopoeial Commission, Ghaziabad, 2007; pp. 1609

3. S. C. Sweetman Martindale - The complete drug reference, $35^{\text {th }}$ ed., Pharmaceutical press, London, 2007; pp. 524, 1241.

4. P. Modamio, C. F. Lastra, O. Montejo, E. L. Marifio, Inter. J. pharm. 130(1), 137, (1996).

5. Ay egul Golcu, J. Anal. Chem. 63(6), 538, (2008).

6. G. Bhavar, V. A. Chatpalliwar, Indian J. Pharm. Sci. 70(3), 395, (2008).

7. British Pharmacopeia; Department of Health and Stationary office under the controller of majesty officer for Health minister UK, Vol. 2, 2005; pp 848.

8. M. Kapetanovic, C.D. Torchin, W.D. Yonekawa, H.J. Kupferberg, J. Chrom. Biomed. Appli.383, 223, (1986).

9. A. M. W. Abdel, F.M.E. Abdel, M.H. Ekram, J. pharm. Biomed. Anal. 13(6), 777, (1995)

10. M. M. Abdul, Bull Fac. Pharm. Cairo Univ. 42 (1), 27 (2004).

11. A. S. Patil, A. A. Shirkhedkar, S. J. Surana, P. S. Nawale Der Pharma Chemica 3(3), 404 (2011). 